\title{
Quantifying the impact of insect predators and parasitoids on populations of the apple ermine moth, Yponomeuta malinellus (Lepidoptera: Yponomeutidae), in Europe
}

\author{
U. Kuhlmann ${ }^{1 *}$, K.P. Carl ${ }^{1}$ and N.J. Mills ${ }^{2}$ \\ 'International Institute of Biological Control, European Station, \\ 1, chemin des Grillons, CH-2800 Delémont, Switzerland: ${ }^{2}$ Center of \\ Biological Control, University of California at Berkeley, USA
}

\begin{abstract}
Life tables were developed to assess the significance of natural enemies on the dynamics of apple ermine moth, Yponomeuta malinellus Zeller, in southwestern Germany and to select parasitoid species for use in the biological control of this pest in Canada. During the study from 1993 to 1995 the abundance of $Y$. malinellus varied from 1.5 to 4.3 tents per 100 leaf clusters indicating that this was a non-outbreak population. From the life tables it was evident that the impact of egg predators accounted for $25-43 \%$ of the total generational mortality of $Y$. malinellus, more than any other known mortality factor. Percent parasitism varied from 18 to $30 \%$, but the impact of parasitoids in relation to the total generational mortality of $Y$. malinellus from the life tables was remarkably constant at $11-14 \%$. The loss of potential fecundity had an important influence on the generational mortality of $Y$. malinellus, but declined from $27 \%$ to $15 \%$ over the course of this study. This decline corresponded with a rise in the net rate of increase $R_{0}$ from 1.35 in 1993 to 6.8 in 1995, despite the impact of insect predators and parasitoids on the generational mortality. Yponomeuta malinellus was attacked by five different obligate primary parasitoids, a single obligate hyperparasitoid, and three facultative hyperparasitoids. Of these, the oligophagous egg-larval parasitoid Ageniaspis fuscicollis Dalman (Encyrtidae) and the oligophagous larval-pupal and pupal parasitoid Herpestomus brunnicornis Gravenhorst (Ichneumonidae) were selected as potential biological control agents for Canada due to a minimal degree of interspecific competition.
\end{abstract}

\section{Introduction}

The apple ermine moth, Yponomeuta malinellus Zeller, is a member of the small genus Yponomeuta Latreille in the family Yponomeutidae (Lepidoptera) and is widely distributed

*Fax: 41324224824

E-mail: u.kuhlmann@cabi.org throughout the Palaearctic region. Recently, Y. malinellus was accidentally introduced into British Columbia (Parker \& Schmidt, 1985) and Washington State, and by 1991, the distribution of $Y$. malinellus had extended into northwestern Oregon (Unruh et al., 1993). In Europe, during the early part of the century, $Y$. malinellus was considered to be among the most destructive defoliators of apple, a pest second in importance to the notorious codling moth (Cydia pomonella 
(Linnaeus), Lepidoptera: Tortricidae) (Faes, 1928; Janecke, 1933). More recently, it has come to be regarded as a minor pest of apples under current management practices in Europe (Galli \& Höhn, 1992). Yponomeuta malinellus does not pose a serious threat to conventional apple production in North America if an early cover spray is used for codling moth control. However, the replacement of insecticide treatment of this latter pest with alternative control measures, such as mating disruption, is already being implemented in large demonstration plots in western North America (Unruh et al., 1993). In this case, Y. malinellus represents a significant threat to apple production in the absence of its coevolved natural enemies (Unruh et al., 1993).

Yponomeuta malinellus is univoltine, and lays batches of 30-50 eggs on apple trees from July to September (Parott \& Schoene, 1912; Thorpe, 1929; Minkiewicz, 1943; Pag, 1959). Hatching takes place in early autumn and the first-instar larvae enter diapause and overwinter in a communal hibernaculum beneath the covering of the egg batch (Ruzaev, 1929; Pag, 1959). In early April, first instar larvae emerge from the hibernacula to mine the adjacent developing leaves (Pag, 1959; Junnikkala, 1960). From the second to the fifth instar, the larvae feed externally of the foliage from within a characteristic communal tent (Pag, 1959; Junnikkala, 1960). During heavy infestations, the tents may envelop the entire tree, resulting in total defoliation and affecting fruit production for several years following an outbreak (Parker $\&$ Schmidt, 1985). The mature larvae spin cocoons that are suspended in rows or clusters within, or adjacent to, the larval tents. Pupal development lasts $10-14$ days and adult emergence occurs from July to early September (Minkiewicz, 1943; Pag, 1959).

Although natural enemies have not always been implicated in the natural control of small ermine moth populations in Europe (e.g. Junnikkala, 1960; Mowat \& Clawson, 1995), there is evidence that parasitoids have played a major role in the dynamics of populations in at least some regions (Eremenko, 1974; Pyörnilä \& Pyörnilä, 1979). Thus, at the request of Agriculture and Agri-Food Canada, $Y$. malinellus populations were intensively sampled in southwestern Germany to determine the impact of natural enemies on the generational mortality of this potential pest in its region of origin and to select potential parasitoids for use in a classical biological control programme in Canada.

\section{Material and methods}

\section{Field sites}

Samples of $Y$. malinellus were collected from two sites in southwestern Germany, where populations had been consistently observed in previous years (Burghause, 1993, personal communication). The first collection site, located at Biebesheim, was a $1.5 \mathrm{~km}^{2}$ grass covered apple orchard situated $100-200 \mathrm{~m}$ from the Rhine River. It contained unpruned, unevenly spaced $(10-20 \mathrm{~m}), 8 \mathrm{~m}$ high trees, ranging from 50 to 60 years old, and was used for a life table study. The second collection site was located near GiessenWettenberg. This orchard contained unpruned, evenly spaced $(10 \mathrm{~m})$ in a row, $3-4 \mathrm{~m}$ high trees, in a grass-annual weed ground cover and was used for additional assessments of parasitism

\section{Estimates of Y. malinellus fecundity}

Pupae of $Y$. malinellus were collected from both Biebesheim and Giessen-Wettenberg, each year from 1993 to 1995 , and kept in rearing cages $(30 \times 30 \times 57 \mathrm{~cm})$ under laboratory conditions at $20^{\circ} \mathrm{C}, 16: 8 \mathrm{~L}: \mathrm{D}, 70-80 \%$ rh to await emergence. Newly emerged moths were collected randomly from the rearing cages and deep-frozen at $-22^{\circ} \mathrm{C}$ for $24 \mathrm{~h}$ to determine the sex ratio and potential fecundity. Potential fecundity was determined by dissection of female abdomens in $70 \%$ alcohol to count the total number of mature, pigmented and unpigmented eggs. A second set of mated females was collected randomly from the rearing cages and kept singly in sleeve cages $(20 \times 30 \mathrm{~cm})$ on several apple trees in Delémont, Switzerland, to obtain data on realized fecundity under field conditions. At the end of the oviposition period (July 1 to early August), all egg batches were counted for each female and the number of eggs in each batch was recorded. The latter was estimated accurately in the field, without destroying the egg batches, using a microscope mounted on a tripod.

\section{Estimates of mortality factors in different developmental stages of $Y$. malinellus}

Freshly laid egg batches of $Y$. malinellus are light yellow in colour and can be detected in the field, but change within a couple of days to a red and then brownish colour and can no longer be easily detected. Due to the difficulty of monitoring naturally-laid egg batches in the field, mortality of $Y$. malinellus egg batches was studied using experimental populations on trees in a small apple orchard in Delémont, Switzerland. Ten $Y$. malinellus adults were placed in each of a series of sleeve cages $(20 \times 35 \mathrm{~cm})$ over branches of the apple trees and left to oviposit for four to five weeks from July 1 each year. After removal of the sleeve cages, all egg batches on the branches were marked with coloured pins and the number of eggs in each batch counted. The egg batches and subsequent egg-batch hibernacula were counted each month from August through to March to monitor their loss due to predation. In March, the egg batches were removed from the branches and the number of live overwintered first instar larvae counted. The loss of egg batches and hibernacula and the difference between the number of eggs in a batch and the number of overwintered first instar larvae in March were combined as egg and hibernaculum mortality.

Sampling was carried out at the two field sites in southwestern Germany from late April to mid June each year, to estimate the number of individuals of $Y$. malinellus and the extent of mortality at each of five life stages (L2-L5 and cocoons). The sample unit most suitable for studying populations of small ermine moths is the leaf cluster (e.g. Leather \& Mackenzie, 1994), as it represents a distinct unit of food resource and all juvenile stages of $Y$. malinellus are found on it. Ten trees selected at random were sampled at each site. Each tree crown was divided into an upper and lower canopy and each half was divided into four equal quadrants according to the four cardinal points of the compass. This provided eight sampling sections within the tree crown. From each section a single branch was selected at random and 30 leaf clusters were examined to determine the number of $Y$. malinellus tents and the number of individuals in each tent. Sampling occurred when the insects were at the mid point of each life stage and selected branches 
were marked to avoid reselection during the assessment of other host life stages. Mortality at each of the life stages was estimated from the differences in $Y$. malinellus abundance in each of the successive samples.

On each sampling occasion, the $Y$. malinellus tents sampled were collected from the field to determine rates of parasitism. Individual tents were placed, with fresh apple foliage, in plastic containers $(10 \times 10 \times 8 \mathrm{~cm})$ with a gauze lid and the $Y$. malinellus were reared outdoors at Delémont, Switzerland until adult moths and parasitoids had emerged. Rearing containers were checked every two days until pupation to supply fresh apple foliage if necessary. After pupation, rearing containers were checked daily to count the number of moths and parasitoids emerging. Percent parasitism was estimated from the number of parasitoid adults (divided by the mean clutch size per host, one for solitary species) divided by the total number of adult moths and parasitoid adult clutches and multiplied by 100 . The estimate of parasitism was based on parasitoid adults emerged, and so may not reflect parasitoid attack rates, although there was no reason to suspect that there was differential mortality of healthy and parasitized hosts.

\section{Construction of life tables}

For the study site at Biebesheim, life tables were constructed for 1993, 1994 and 1995 with the following columns: 1 , the number of $Y$. malinellus present in each life stage, $d_{x}$ the number of $Y$, malinellus dying during each life stage, $\mathrm{Fd}$ the factor(s) responsible for the $Y$. malinellus mortality at each life stage, and the corresponding marginal death rate, apparent mortality, and k-value. More detailed descriptions of columns used are given in Southwood (1978) and Bellows et al. (1992).

Percent loss of $Y$. malinellus egg batches and hibernacula was used both as a mortality factor (due primarily to predation) in the egg stage and to calculate, from the number of first instar larvae, the number of $Y$. malinellus eggs. The results of the sampling programme described above were used to obtain data on the number of individuals of $Y$. malinellus in each larval stage. Although parasitism could be detected from the rearing of $Y$. malinellus samples at all larval stages, parasitoid-induced mortality ("parasitism') in the life tables was estimated from the fifth instar larval and cocoon samples only. The number of hosts in the pupal stage was estimated by subtracting the number of hosts killed by larval parasitoids in the fifth instar from the number of $Y$. malinellus cocoons sampled on the final sampling date. The number of $Y$. malinellus adults in the life table was estimated from the number reared from the sampled cocoons. Fecundity estimates of $Y$. malinellus were introduced into life tables from estimates of sex ratio and 'potential fecundity' (from dissection) of emerged females, and 'realized fecundity' from individual females in sleeve cages. The net reproductive rate $\left(\boldsymbol{R}_{0}\right)$ was estimated as the ratio of the expected egg population in the following generation to the egg population at the beginning of the

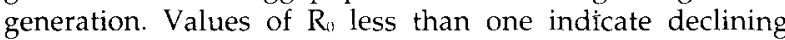
populations, while values greater than one indicate increasing populations. The total generational mortality $(K)$ was calculated from the sum of the individual k-values associated with each life stage, allowing each stage mortality or each mortality factor to be expressed as a percentage of the generational mortality $\left(100 \mathrm{k}_{\mathrm{i}} / \mathrm{K}\right)$

\section{Results}

\section{Estimates of $\mathrm{Y}$. malinellus fecundity}

The following sex ratios of $Y$. malinellus (proportion of females) were determined: $0.47(\mathrm{n}=184)$ in 1993, 0.51 $(n=415)$ in 1994 , and $0.49(n=106)$ in 1995. From dissection of emerging $Y$. malinellus females the mean fecundity was $115 \pm 4.5 \mathrm{SE}(\mathrm{n}=19)$ and ranged from 72 to 153 eggs, giving 153 as an estimate of the potential fecundity. The mean realized fecundity of emerging females in the field was 52 $(+5.9 \mathrm{SE}, \mathrm{n}=22)$ in $1993,75(+9.4 \mathrm{SE}, \mathrm{n}=20)$ in 1994 , and $107.3( \pm 8.3 \mathrm{SE}, \mathrm{n}=20)$ in 1995 . The number of eggs per batch in the field was on average $39.3( \pm 1.2 \mathrm{SE}, \mathrm{n}=195)$ in 1993 , $41.4( \pm 1.1 \mathrm{SE}, \mathrm{n}=238)$ in 1994 , and $48.6( \pm 2.7 \mathrm{SE}, \mathrm{n}=42)$ in 1995.

Estimates of mortality factors in different developmental stages of $Y$. malinellus

Predation of $Y$. malinellus egg batches and hibernacula by unknown insect predators started soon after oviposition. It was determined that mortality caused by insect predators reached $64 \%$ in $1992 / 93,64 \%$ in $1993 / 94$ and $65 \%$ in $1994 / 95$. Although no systematic observations were made of the predators responsible, both the European earwig, Forficula auricularia Linnaeus (Dermaptera: Forficulidae), and larvae of Chrysoperla carnea (Stephens) (Neuroptera: Chrysopidae) were observed to feed on egg batches and hibernacula.

The sampling programme provided estimates each year of $Y$. malinellus tents per 30 leaf clusters, individuals per tent and percent parasitism (separately for each parasitoid species present) for each larval instar of $Y$. malinellus both for Biebesheim (table 1) and for Giessen (table 2). Nine parasitoid species of the hymenopteran families Ichneumonidae (five species), Encyrtidae (one species), Eulophidae (one species), and Elasmidae (one species) and of the dipteran family Tachinidae (one species) were identified (table 3). Five of the parasitoid species were obligate primary parasitoids, but Mesochorus sp. (Hymenoptera: Ichneumonidae) was an obligate hyperparasitoid and Baryscapus evonymellae (Bouché) (Hymenoptera: Eulophidae), Elasmus albipennis Thompson (Hymenoptera: Elasmidae) and Itoplectis maculator Fabricius (Hymenoptera: Ichneumonidae) acted as facultative hyperparasitoids. Parasitism by several of the parasitoid species at Giessen appeared not to occur as early in the life cycle as at Biebesheim and two of the parasitoids, Eurysthaea scutellaris Robineau-Desvoidy (Diptera: Tachinidae) and Agrypon canaliculatum Ratzeburg (Hymenoptera: Ichneumonidae), were entirely absent from Giessen.

Primary parasitoid species with the same pattern of host utilization can be grouped into parasitoid guilds to represent the structure of the parasitoid community. From the stage-specific patterns of parasitism (tables 1, 2) five parasitoid guilds of $Y$. malinellus were recognized: (1) egg-larval endoparasitoid, (2) larval-prepupal endoparasitoid, (3) larval-pupal endoparasitoid, (4) larval/prepupal ectoparasitoid, and (5) pupal endoparasitoid (fig. 1). The polyembryonic egg-larval endoparasitoid Ageniaspis fuscicollis Dalman (Hymenoptera: Encyrtidae) which attacked host eggs, was detected in all larval instars, and killed the host during the final larval instar. This univoltine species mummifies the final instar larvae and produces 80 parasitoid 


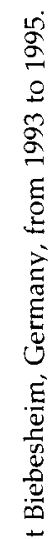

$\pi$

要

$\frac{\overrightarrow{3}}{8}$

苞

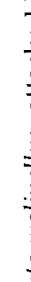

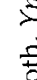

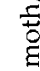

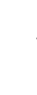

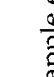

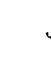

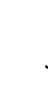

(1)

列
.

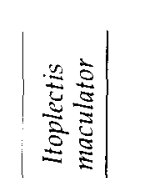


Life tables for the apple ermine moth

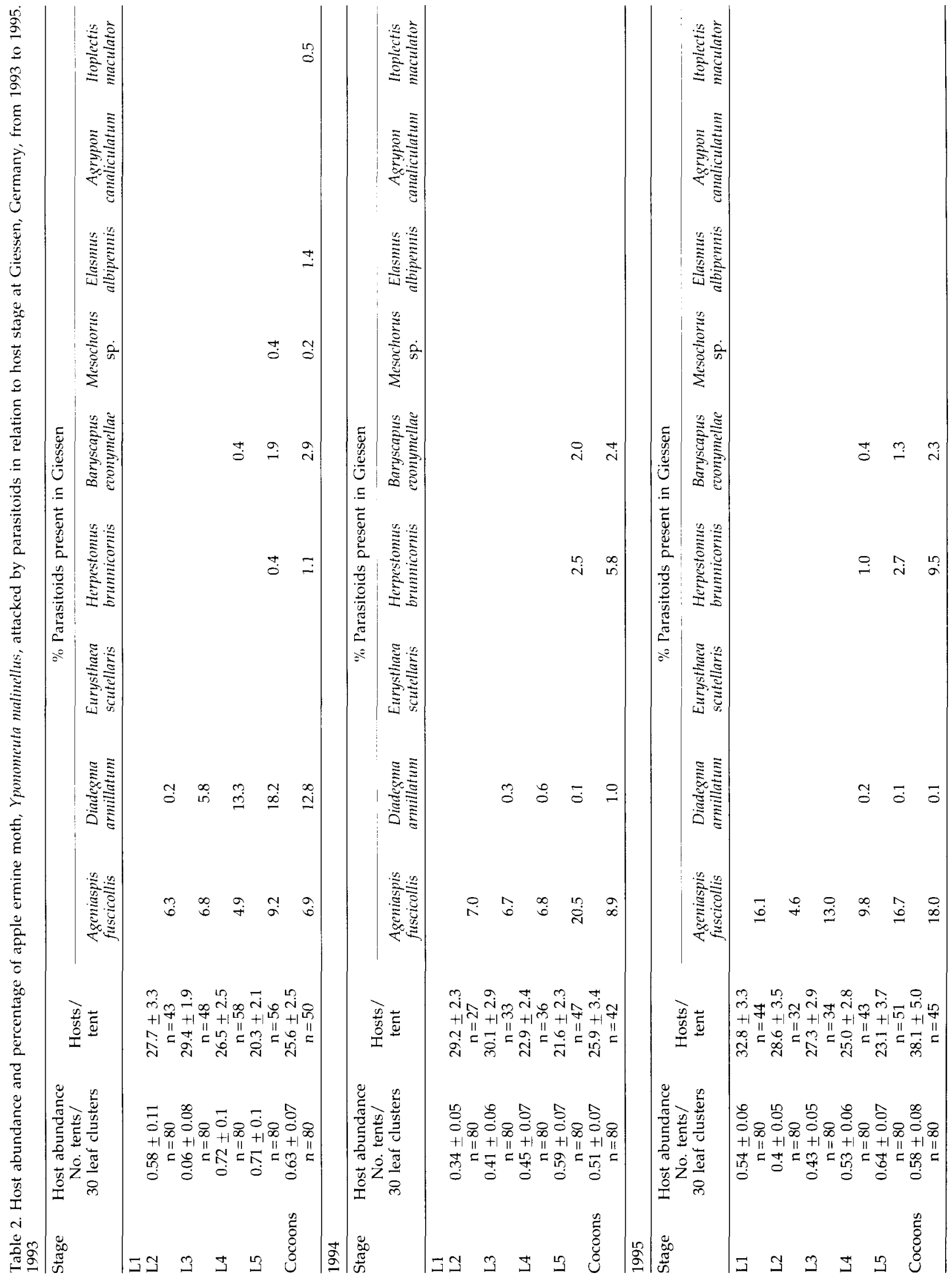


Table 3. Primary parasitoids and hyperparasitoids reared from the apple ermine moth, Yponomeuta malinellus, at two sites in Germany from 1993 to 1995.

\begin{tabular}{|c|c|}
\hline \multicolumn{2}{|c|}{$\begin{array}{l}\text { Parasitoid and hyperparasitoid species } \\
\text { of the apple ermine moth, Yponomeuta malinellus }\end{array}$} \\
\hline $\begin{array}{l}\text { Obligate primary parasitoids } \\
\text { Ichneumonidae } \\
\text { Diadegma armillatum Gravenhorst } \\
\text { Herpestomus brunnicornis Gravenhorst } \\
\text { Agrypon canaliculatum Ratzburg }\end{array}$ & $\begin{array}{l}\text { Encyrtidae } \\
\text { Ageniaspis fuscicollis Dalman } \\
\text { Tachinidae } \\
\text { Eurysthaea scutellaris Robineau-Desvoidy }\end{array}$ \\
\hline $\begin{array}{l}\text { Obligate hyperparasitoids } \\
\text { Ichneumonidae } \\
\text { Mesochorus sp. }\end{array}$ & \\
\hline $\begin{array}{l}\text { Facultative hyperparasitoids } \\
\text { Ichneumonidae } \\
\quad \text { Itoplectis maculator Fabricius } \\
\text { Eulophidae } \\
\text { Baryscapus evonymellae Bouché }\end{array}$ & $\begin{array}{l}\text { Elasmidae } \\
\text { Elasmus albipennis Thompson }\end{array}$ \\
\hline
\end{tabular}

individuals per host. The solitary larval-prepupal endoparasitoid Diadegma armillatum (Gravenhorst) (Hymenoptera: Ichneumonidae) attacked as early as the second larval instar, but as percent parasitism increased in samples up to the fifth larval instar, it appeared able to attack a broad range of larval instars. It killed $Y$. malinellus hosts as prepupae producing an oval, brown cocoon, outside or inside the cocoon of $Y$. malinellus and was itself attacked by the hyperparasitoid Mesochorus sp. The gregarious larval/prepupal ectoparasitoid E. albipennis attacked $Y$. malinellus as fifth instar larvae protected in a tent or as prepupae in cocoons. Elasmus albipennis is also known to act as a facultative hyperparasitoid of the cocoon stage of D. armillatum (Dijkerman et al., 1986). The solitary larval-pupal endoparasitoids E. scutellaris, A. canaliculatum and Herpestomus brunnicornis Gravenhorst (Hymenoptera: Ichneumonidae) and the gregarious larval-pupal endoparasitoid $B$. evonymellae attacked $Y$. malinellus larvae from the third or fourth larval instar but only killed their host in the pupal stage. Baryscapus evonymellae is also known to be a facultative hyperparasitoid, parasitizing D. armillatum and Mesochorus sp. (Dijkerman et al., 1986; Graham, 1991). Herpestomus brunnicornis continued to attack $Y$. malinellus in the pupal stage which, together with the solitary I. maculator, form the pupal endoparasitoid guild. Itoplectis maculator is also known to be a facultative hyperparasitoid of other parasitoids developing within Y. malinellus pupae (Zwölfer, 1963).

\section{Construction of life tables}

Life tables were constructed for the $Y$. malinellus study site at Biebesheim for 1993, 1994, and 1995 (table 4). They include the life stages directly sampled from the field (L1 to cocoon) and were completed, using independent observations from Delémont, for egg and hibernaculum mortality and the realized fecundity of $Y$. malinellus females. The number of $Y$. malinellus eggs was calculated from the number of first instar larvae in leaf mines (L1) and the independent estimates of egg/hibernaculum mortality. The number of $Y$. malinellus pupae was calculated from the number of cocoons sampled in the field minus the number of individuals dying from parasitism as prepupae. The maximum number of eggs in a dissected female of $Y$. malinellus, reared from cocoons collected at Biebesheim, represented the potential fecundity and was used to calculate the potential progeny. The realized fecundity was estimated from emerging females sleeve-caged in Delémont and was used to calculate the actual progeny for the following generation. The net reproductive rate of increase $\left(R_{11}\right)$ was

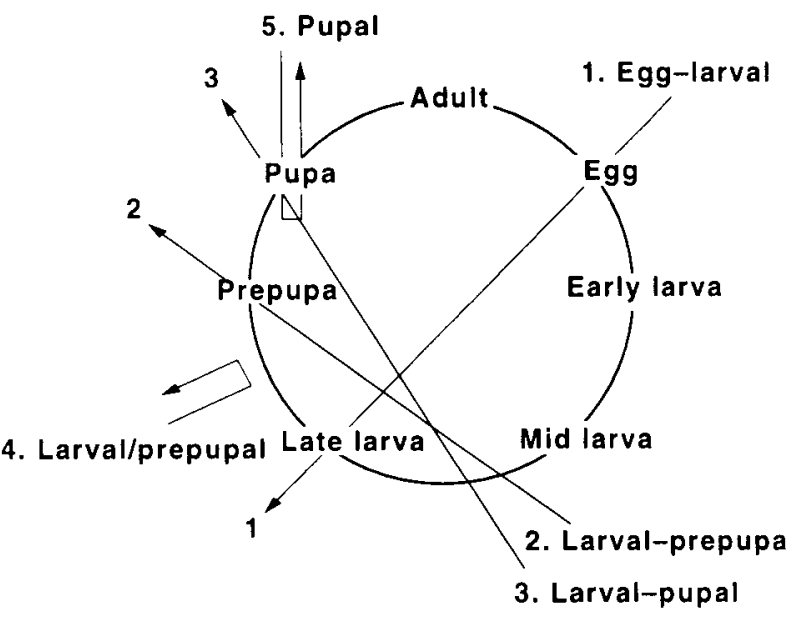

1. Egg-larval endoparasitoid guild

Ageniaspis fuscicollis (Hymenoptera: Encyrtidae)

2. Larval-prepupal endoparasitoid guild

Diadegma armillatum (Hymenoptera: Ichneumonidae)

3. Larval-pupal endoparasitoid guild

Herpestomus brunnicornis (Hymenoptera: Ichneumonidae) Agrypon canaliculatum (Hymenoptera: Ichneumonidae) Baryscapus evonymellae (Hymenoptera: Eulophidae) Eurysthaea scutellaris (Diptera: Tachinidae)

4. Larval/prepupal ectoparasitoid guild

Elasmus albipennis (Hymenoptera: Elasmidae)

5. Pupal endoparasitoid guild

Itoplectis maculator (Hymenoptera: Ichneumonidae)

Herpestomus brunnicornis (Hymenoptera: Ichneumonidae)

Fig. 1. Parasitoid guilds of the apple ermine moth, Yponomenta malinellus, defined by their pattern of host utilization. Arrows connect the host stage attacked to the host stage killed by the parasitoid, and arrows passing through the host circle indicate endoparasitic development, whereas those remaining outside the circle indicate ectoparasitic development. 
estimated from the ratio of the actual progeny to eggs and was 1.35 in 1993, 2.43 in 1994 and 6.8 in 1995.

Parasitism between the fifth instar larval and pupal stages was caused by $A$. fuscicollis, D. armillatum and $E$. albipennis. Mortality due to $A$. fuscicollis was estimated from the combined fifth instar larval and cocoon samples, as parasitized larvae often died in rearing. Parasitism due to $D$. armillatum was estimated from the fifth instar larval samples and included hosts from which the obligate hyperparasitoid Mesochorus sp. emerged. Parasitism by

Table 4. Life tables for the apple ermine moth, Yponomeuta malinellus, in Biebesheim in Germany from 1993 to 1995. 1993

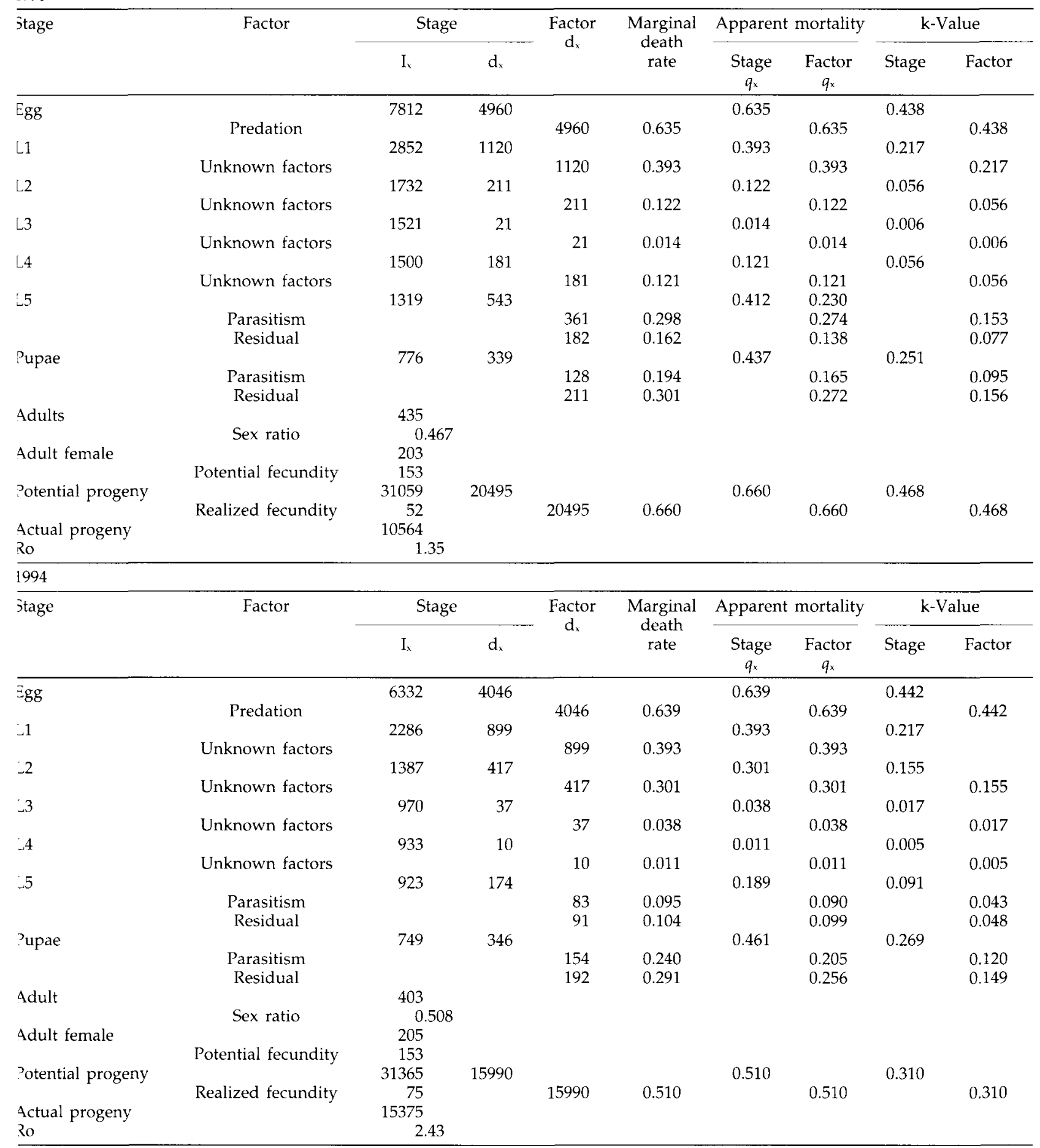


Table 4-continued.

1995

\begin{tabular}{|c|c|c|c|c|c|c|c|c|c|}
\hline \multirow[t]{2}{*}{ Stage } & \multirow[t]{2}{*}{ Factor } & \multicolumn{2}{|c|}{ Stage } & \multirow{2}{*}{$\begin{array}{c}\text { Factor } \\
\mathrm{d}_{\mathrm{x}}\end{array}$} & \multirow{2}{*}{$\begin{array}{c}\text { Marginal } \\
\text { death } \\
\text { rate }\end{array}$} & \multicolumn{2}{|c|}{ Apparent mortality } & \multicolumn{2}{|c|}{ k-Value } \\
\hline & & $\mathrm{I}_{x}$ & $\mathrm{~d}_{2}$ & & & $\begin{array}{c}\text { Stage } \\
q .\end{array}$ & $\begin{array}{c}\text { Factor } \\
q\end{array}$ & Stage & Factor \\
\hline Egg & \multirow[b]{2}{*}{ Predation } & 10167 & 6578 & \multirow[b]{2}{*}{6578} & \multirow[b]{2}{*}{0.647} & 0.647 & \multirow[b]{2}{*}{0.647} & 0.452 & \multirow[b]{2}{*}{0.452} \\
\hline \multirow[t]{2}{*}{ L1 } & & 3589 & 438 & & & 0.122 & & 0.056 & \\
\hline & Unknown factors & & & 438 & 0.122 & & 0.122 & & 0.056 \\
\hline L2 & & 3151 & 475 & \multirow[b]{2}{*}{475} & \multirow[b]{2}{*}{0.151} & 0.151 & \multirow[b]{2}{*}{0.151} & 0.072 & \multirow[b]{2}{*}{0.072} \\
\hline \multirow[t]{2}{*}{ L3 } & Unknown factors & 2676 & 6 & & & 0.002 & & 0.001 & \\
\hline & Unknown factors & & & 6 & 0.002 & & 0.002 & & 0.001 \\
\hline L4 & Unknown factors & 2670 & 53 & 53 & 0.02 & 0.02 & \multirow[t]{2}{*}{0.02} & 0.009 & \multirow[t]{2}{*}{0.009} \\
\hline \multirow[t]{2}{*}{ L5 } & & 2617 & 281 & & & 0.108 & & 0.049 & \\
\hline & $\begin{array}{l}\text { Paratism } \\
\text { Residual }\end{array}$ & & & $\begin{array}{l}167 \\
114\end{array}$ & $\begin{array}{l}0.066 \\
0.046\end{array}$ & & $\begin{array}{l}0.064 \\
0.044\end{array}$ & & $\begin{array}{l}0.029 \\
0.020\end{array}$ \\
\hline Pupae & & 2336 & 1020 & & & 0.437 & & 0.249 & \\
\hline & Parasitism & & & 390 & 0.196 & & 0.167 & & 0.095 \\
\hline & Residual & & & 630 & 0.299 & & 0.270 & & 0.154 \\
\hline Adult & & 1316 & & & & & & & \\
\hline & Sex ratio & 0.4 & & & & & & & \\
\hline Adult female & & 646 & & & & & & & \\
\hline Potential progeny & Potential fecundity & $\begin{array}{r}153 \\
98838\end{array}$ & 29716 & & & 0301 & & 0155 & \\
\hline & Realized fecundity & 107 & & 29716 & 0.301 & & 0.301 & & 0.155 \\
\hline Actual progeny & & 69122 & & & & & & & \\
\hline Ro & & 6.8 & & & & & & & \\
\hline
\end{tabular}

E. albipennis was estimated from the cocoon samples, but as this species is a facultative hyperparasitoid a proportion of the hosts from which E. albipennis emerged were transferred to parasitism by $D$. armillatum, under the assumption that it attacked primary and secondary hosts in proportion to their abundance. Similarly, $B$. evonymellae can be a facultative parasitoid of $D$. armillatum and using the same assumption of proportional attack, a proportion of hosts from which B. evonymellae emerged were also transferred to parasitism by $D$. armillatum. Apparent parasitism during the fifth instar larval and prepupal stages reached $27 \%$ in $1993,9 \%$ in 1994 and $6 \%$ in 1995 .

Rates of parasitism in the cocoon stage, due to $B$. evonymellae, E. scutellaris, A. canaliculatum, I. maculator and H. brunnicornis, were estimated from the cocoon samples and were based on the number of $Y$. malinellus pupae. Apparent parasitism by $B$. evonymellae and $I$. maculator were proportionally reduced due to potential hyperparasitism of D. armillatum and other pupal stage parasitoids respectively.
Apparent parasitism in the pupal stage was $17 \%$ in 1993, 21\% in 1994 , and $17 \%$ in 1995.

The impact of predation and parasitism on the generational mortality of $Y$. malinellus was determined at Biebesheim in 1993-1995, using the k-values from the life tables. The generational mortality $\left(\mathrm{K}=\Sigma \mathrm{k}_{\mathrm{i}}\right)$ was 1.72 in 1993, 1.51 in 1994 and 1.04 in 1995. The percentage of the generational mortality due to loss of potential fecundity, predation of eggs and hibernacula and parasitism $\left(100 \mathrm{k}_{\mathrm{i}} / \mathrm{K}\right)$ are presented in table 5 . Predation had the greatest impact on the $Y$. malinellus population studied, although it equalled the loss of potential fecundity in the first year of the study. The impact of parasitism had the leasi impact of the known mortalities and this remained remarkably constant over the three-year period. The combined effect of natural enemies at $40-55 \%$ of the generational mortality of the $Y$. malinellus population was substantially greater than the loss of potential fecundity at $15-27 \%$.

Table 5. Loss of potential fecundity and impact of natural enemies on the generational mortality of the apple ermine moth, Yponomenta malinellus, at Biebesheim in Germany from 1993 to 1995.

\begin{tabular}{|c|c|c|c|c|}
\hline \multirow[t]{2}{*}{ Year } & \multirow{2}{*}{$\begin{array}{l}\text { Host fecundity } \\
\text { losses }(\%)\end{array}$} & \multicolumn{3}{|c|}{ Impact of natural enemies (\%) } \\
\hline & & Egg predators & Parasitoids & Total \\
\hline 1993 & 27.2 & 25.4 & 14.4 & 39.8 \\
\hline 1994 & 20.6 & 29.3 & 10.8 & 40.1 \\
\hline 1995 & 14.9 & 43.3 & 11.9 & 55.2 \\
\hline mean & 20.9 & 32.7 & 12.4 & 45.0 \\
\hline
\end{tabular}




\section{Discussion}

We have presented here the results of a life table study to determine the impact of natural enemies on a population of $Y$. malinellus over a three year period in southwestern Germany. This approach was used to provide data for the selection of natural enemies for use in a biological control programme for $Y$. malinellus in Canada.

\section{Factors influencing the generational mortality of Y. malinellus}

The abundance of $Y$. malinellus varied from 1.8 to 4.3 tents per 100 leaf clusters in Biebesheim and from 1.5 to 2.2 tents per 100 leaf clusters in Giessen. These densities were zenerally below the traditional control threshold of 3-5 larval tents per 100 leaf clusters (Baggiolini et al., 1980) and would not have been considered for control treatments as no economic threshold values exist for $Y$. malinellus in central Europe because of its reduced importance today under zurrent pest management practices (Galli \& Höhn, 1992).

Insect predation obviously played an important role in the reduction of $Y$. malinellus egg and hibernaculum populations. From the life tables, it is evident that the impact of egg predators accounted for $25-43 \%$ of the total zenerational mortality of $Y$. malinellus, more than any other known mortality factor. Unfortunately, no systematic observations of the predator species responsible for the mortality of egg batches and hibernacula were possible. However, based on the results of this study, and according to Unruh et al. (1993) and Smith (1994, personal communization) endemic polyphagous predators in Europe and in the western United States and Canada do produce significant mortality in $Y$. malinellus populations. These generalist predators may be largely responsible for preventing even more damaging levels of $Y$. malinellus in the western United States (Unruh et al., 1993).

Percent parasitism, in the present study, varied from 21 to $26 \%$ at Biebesheim and from 18 to $30 \%$ at Giessen. However, the impact of parasitoids in relation to the total zenerational mortality of $Y$. malinellus from the life tables at Biebesheim was remarkably constant at $11-14 \%$. All other studies of $Y$. malinellus in its natural range have considered only percent parasitism. These studies reported values ranging from 30 to 98\% (Ruzaev, 1929; Thorpe, 1930; Voukassovitch, 1933; Bilanovski, 1938; Iren, 1952; Vaclav, 1958; Junnikkala, 1960; Balachowsky, 1966; Aleksidze \& Bezhanishvili, 1974; Eremenko, 1974; Dijkerman et al., 1986; Tkachev, 1986).

We estimated the average potential fecundity of $Y$. malinellus to be 115 , a value that is almost identical to the sstimate of 117 for Y. evonymellus (Linnaeus) (Lepidoptera: Yponomentidae) (Leather \& MacKenzie, 1994). Failure of populations to realize their potential fecundity can be a major factor contributing to changes in numbers of insects setween generations (Banerjee, 1979; Courtney \& Duggan, 1983; Preszler \& Price, 1988; Price et al., 1990). The loss of potential fecundity was a significant component of the life tables of $Y$. malinellus, but declined from $27 \%$ to $15 \%$ of the Jenerational mortality over the course of this study. Kuhlmann (1995) demonstrated that the fecundity of $Y$. malinellus is significantly influenced by the mean daily temperature during the oviposition period. The number of egg batches laid per $Y$. malinellus female increased significantly with higher mean daily temperatures during the oviposition period.

Parasitoid community of Y. malinellus and selection of biological control agents

A natural parasitoid community is defined as an assemblage of primary parasitoid species that attack the population of a particular host species in a given locality (Ehler, 1992; Mills, 1992, 1994a). In the present study, Y. malinellus populations were attacked by eight different parasitoid species at Biebesheim and by six parasitoid species at Giessen. The parasitoid species represent five different parasitoid guilds, somewhat less than the eight parasitoid guilds that have been recognized for the Yponomeutidae as a whole (Hawkins \& Mills, 1996). Three of the guilds are occupied by a single parasitoid species, with the larval-pupal endoparasitoid and pupal endoparasitoid guilds being occupied by four and two species respectively. The most consistent parasitoid species found attacking $Y$. malinellus throughout its native range are the egg-larval endoparasitoid A. fuscicollis, the larval-prepupal endoparasitoid $D$. armillatum, and the larval-pupal or pupal endoparasitoid $H$. brunnicornis. These same parasitoids were responsible for the greatest levels of parasitism at both Biebesheim and Geissen in the present study. Other parasitoids reported from $Y$. malinellus in Europe that were not found during the present study include the tachinids Bactromyia aurulenta (Meigen) (Pag, 1959; Dijkerman et al., 1986) and Bessa selecta (Meigen) (Pag, 1959), the eulophid Baryscapus galactopus (Ratzeburg) (Junnikkala, 1960), and the ichneumonids Pimpla turionellae (Linnaeus) (Junnikkala, 1960) and Agrypon anxium (Wesmael) (Dijkerman et al., 1986).

In the selection of parasitoids for use in a classical biological control programme, it is important to exclude antagonistic species in the reconstruction of a parasitoid community for the target region of a pest, as they can prevent the most effective parasitoids from realizing their potential as control agents (Waage \& Mills, 1992; Mills, 1994b). Considering the natural parasitoid community of $Y$. malinellus, competitive interactions are minimal between the egg-larval parasitoid and the larval-pupal guilds, and of course interspecific competition is excluded between the egg-larval and the pupal parasitoid guilds. Ageniaspis fuscicollis is the only member of the egg-larval endoparasitoid and H. brunnicornnis in the only member of the pupal endoparasitoid guild that is not a facultative hyperparasitoid. Although H. brunnicornis is also a larval-pupal endoparasitoid and can attack $Y$. malinellus from the fourth instar larvae onwards, it preferentially attacks fifth instar larvae and pupae, with a maximum rate of parasitism in the pupal stage. Overlap between A. fuscicollis and H. brunnicornis is likely to be confined to the fourth larval instar of $Y$. malinellus because $H$. brunnicornis is unlikely to attack a fifth instar host larva that is close to mummification by $A$. fuscicollis. This degree of overlap is minimal and so these two specific parasitoids could be safely introduced simultaneously in a classical biological control programme against $Y$. malinellus. Both parasitoid species are restricted in their host range to the genus Yponomeuta, they are univoltine and therefore well-synchronized with the development of their host, and occupy a wide geographic range (for details of $H$. brunnicornis see Kuhlmann, 1996). The ichneumonid $D$. armillatum was not considered as a biological control agent 
despite its high impact due to the fact that it is known to be a polyphagous parasitoid of microlepidopteran hosts (Herting \& Simmonds, 1982). The egg-larval parasitoid A. fuscicollis has already been introduced into Canada and its impact is being determined in British Columbia (Cossentine, 1996, personal communication).

\section{Acknowledgements}

We greatly appreciated the help of Andreas Kählert, Andrea Raps, Dirk Babendreier, Stefanie Erb, and Heike Gose with the laboratory and field work. They made an enthusiastic team with which it was a pleasure to work. We wish to thank the following specialists for identification of parasitoids: Klaus Horstmann (Ichneumonidae), Stefan Vidal (encyrtids, eulophids, and elasmids), and HansPeter Tschorsnig (tachinids). This study was supported by Agriculture and Agri-Food Canada.

\section{References}

Aleksidze, G.N. \& Bezhanishvili, T.D. (1974) Parasites of leaf-eating insects. Zashchita Rastenii 10, 24-25 (in Russian, English abstract).

Baggiolini, M., Keller, E., Milaire, H.G. \& Steiner, H. (1980) Visuelle Kontrollen im Apfelanbau. 3. Aufl. 104 pp. France, Generalsekretariat IOBC/wprs.

Balachowsky, A.S. (1966) Entomologie appliquée à l'agriculture, Tome II. Lépidoptères Vol.1, $145 \mathrm{pp}$. France, Masson \& Cie.

Banerjee, B. (1979) A key-factor analysis of population fluctuations in Andraca bipunctata Walker (Lepidoptera: Bombycidae). Bulletin of Entomological Research 69, 195-201.

Bellows, T.S., van Driesche, R.G. \& Elkinton, J.S. (1992) Life-table construction and analysis in the evaluation of natural enemies. Annual Review of Entomology 37, $587-614$.

Bilanovskii, I.D. (1938) Zoological factors that limited the increase of the apple ermine moth in the province of Kiew in the years 1934-1936. Traveaux Museum de Zoologie Academique et Scientifique d'Ukraine 21/22, 153-166 (in Ukrainian, German abstract).

Courtney, S.P. \& Duggan, A.E. (1983) The population dynamics of the orange tip butterfly, Anthocharis cardamines, in Britain. Ecological Entomology 8, 271-281.

Dijkerman, H.J., de Groot, J.M.B. \& Herrebout, W.M. (1986) The parasitoids of the genus Yponomeuta Latreille (Lepidoptera, Yponomeutidae) in the Netherlands. Proceedings of the Koninklijke Nederlandse Akademie van Wetenschappen Series C 89, 379-398.

Ehler, L.E. (1992) Guild analysis in biological control. Environmental Entomology 21, 26-40.

Eremenko, T.S. (1974) Ageniaspis - a parasite of the apple moth. Zashchita Rastenii 11, 25 (in Russian, English abstract).

Faes, H. (1928) La lutte contre les chenilles fileuses ou chenilles d'Hyponomeutes. Annales Agriculture de Suisse 29, 520-533.

Galli, P. \& Höhn, H. (1992) Visuelle Kontrollen im Apfelanbau. 4. Aufl. 104 pp. France, Generalsekretariat IOBC/wprs.

Graham, M.W.R. (1991) A reclassification of the European Tetrastichinae (Hymenoptera: Eulophidae): revision of remaining genera. Memoirs of the American Entomological Institute 49, 1-36.
Hawkins, B.A. \& Mills, N.J. (1996) Variability in parasitoid community structure. Journal of Animal Ecology 65, 501-516.

Herting, B. \& Simmonds, F.J. (1982) A catalogue of parasites and predators of terrestrial arthropods, Section B, enemy/host or prey, Volume II Hymenoptera Terebrantia, 223 pp. Farnham Royal, UK, Commonwealth Agriculture Bureaux.

Iren, Z. (1952) The native parasites of small ermine moth Hyponomeuta padella and codling moth Carpocapsa pomonella larvae in Ankara (Turkey). Bitki Koruma 4, 16-18.

Janecke, O. (1933) Gespinstmotten als Grosschädlinge an Obstbäumen. Arbeiten der biologischen Reichanstalt für Land-und Forstwissenschaften 20, 431-441.

Junnikkala, E. (1960) Life history and insect enemies of Hyponomeuta malinellus Zell. (Lep., Hyponomeutidae) in Finland. Annales Zoologici Societatis Zoologicae Botanicae Fennicae "Vanamo" 21, 3-44.

Kuhlmann, U. (1995) Measuring and understanding the impact of insect predators and parasitoids on populations of the Apple Ermine Moth, Yponomeuta malinellus, (Lepidoptera: Yponomeutidae). $\mathrm{PhD}$ thesis University of Kiel, Germany, $101 \mathrm{pp}$.

Kuhlmann, U. (1996) Biology and ecology of Herpestomus brunnicornis (Hymenoptera: Ichneumonidae), a potential biological control agent of the apple ermine moth (Lepidoptera: Yponomeutidae). International journal of Pest Management 42, 131-138.

Leather, S.R. \& MacKenzie, G.A. (1994) Factors affecting the population development of the bird cherry ermine moth, Yponomeuta evonymellus (L.). The Entomologist 113, 86-105.

Mills, N.J. (1992) Parasitoid guilds, life-styles, and host ranges in the parasitoid complexes of tortricid hosts (Lepidoptera: Tortricoidea). Environmental Entomology 21, 230-239.

Mills, N.J. (1994a) Parasitoid guilds: defining the structure of the parasitoid communities of endopterygote insect hosts. Environmental Entomology 23, 1066-1083.

Mills, N.J. (1994b) The structure and complexity of parasitoid communities in relation to biological control. pp. 397-417 in Hawkins, B.A. \& Sheehan, W. (Eds) Parasitoid community ecology. Oxford, Oxford University Press.

Minkiewicz, S. (1943) Die Apfelgespinstmotte - Hyponomeuta padells L. ssp. biol. malinellus Zeller. Berichte der landwirtschaftlichen Forschungsanstalt General Gouvernement $P u$ lawy 1, 104-128.

Mowat, D.J. \& Clawson, S. (1995) Natural control of the small ermine moth Yponomeuta padella. Agriculture, Ecosystems and Environment 52, 93-102.

Pag, H. (1959) Hyponomeuta-Arten als Schädlinge im Obstbau. Ein Beitrag zur Biology, Ökologie und Bekämpfung, unter besonderer Berücksichtigung des Arten-Rassenproblems. Zeitschrift fiir angewandte Zoologie 46, 129-189.

Parker, D.J. \& Schmidt, A.C. (1985) Apple ermine moth, Yponomeuta malinellus. $8 \mathrm{pp}$. Report of Agriculture Canada Plant Health Division, Ottawa, Ontario.

Parrot, P.J. \& Schoene, W.J. (1912) The apple and cherry tree ermine moth. New York Agricultural Experiment Station (Geneva, N.Y.) Technical Bulletin 24, 1-39.

Prezler, R.W. \& Price, P.W. (1988) Host quality and sawfly populations: a new approach to life table analysis. Ecology 69, 2012-2020.

Price, P.W., Cobb, N., Craig, T.P., Fernandes, G.W. \& Itami, J.K. (1990) Insect herbivore populations dynamics on trees and 
shrubs: new approaches relevant to latent and eruptive species and life table development. pp. 1-38 in Bernays, E.A. (Ed.) Insect-plant interactions. Boca Raton, Florida, CRC Press.

Pyörnilä, M. \& Pyörnilä, A. (1979) Role of parasitoids in termination of a mass occurrence of Yponomeuta evonymellus (Lepidoptera: Yponomeutidae) in northern Finland. Notulae Entomologicae 59, 133-137.

Ruzaev, K.S. (1929) Notes on the biology of Hyponomeuta malinella Zeller. Plant Protection Leningrad 6, 213-219 (in Russian, English abstract).

Southwood, T.R.E. (1978) Ecological methods with particular reference to the study of insect populations. 2nd edn, 524 pp. London, Chapman \& Hall.

Thorpe, W.H. (1929) Biological races in Hyponomeuta padella L. Iournal of the Limean Society (Zoology) 37, 489-492.

Thorpe, W.H. (1930) The natural control of Hponomeuta padellus, L. Proceedings of the Entomological Society of London $5,28-30$.

Tkachev, V.M. (1986) Protection of apple. Zashchita Rastenii 5, 24-25 (in Russian, English abstract).
Unruh, T.R., Congdon, B.D. \& LaGasa, E. (1993) Yponomeuta malinellus Zeller (Lepidoptera: Yponomeutidae), a new immigrant pest of apples in the Northwest: phenology and distribution expansion, with notes on efficacy of natural enemies. Pan-Pacific Entomologist 69, 57-70.

Vaclav, V. (1958) The importance of parasites of the apple and plum moths in reducing populations of these important pests in Bosnia and Herzegovina. Plant Protection Beograd 49-50, 113-119.

Voukassovitch, P. (1933) Contribution a l'etude des parasites et hyperparasites d'Hyponomeuta malinellus Zell. Revue de Zoologie Agricole et Appliquée 31, 108-183.

Waage, J.K. \& Mills, N.J. (1992) Biological control. pp. 412-430 in Crawley, M.J. (Ed.) Natural enemies. Oxford, Blackwell Scientific Publications.

Zwölfer, H. (1963) Untersuchungen über die Struktur von Parasiten-Komplexen bei einigen Lepidopteren. Zeitschrift für Angewandte Entomologie 51, 346-357.

(Accepted 24 October 1997) c. CAB INTERNATIONAL, 1998 